\title{
DIREITO FUNDAMENTAL AO NOME
}

\author{
Janice Silveira Borges ${ }^{1}$
}

Resumo: As novas decisões dos Tribunais Internacionais levaram a uma releitura dos fundamentos jurídicos que embasam o direito ao nome. A perspectiva civilistica cedeu para uma jusconstitucionalista com um forte viés dos direitos fundamentais, dentro de uma visão da dignidade da pessoa humana e uma proteção eficaz, seja de modo direto ou indireto do referido direito, abrindo-se a novos argumentos para que de fato isso ocorra.

Palavras-chave: Direito ao Nome; Dignidade da Pessoa Humana; Direito Constitucional; Direitos Fundamentais; Direitos Humanos.

\section{FUNDAMENTAL RIGHT TO NAME}

Abstract:The new decisions of the International Courts have led to a re-reading of the legal bases that underpin the right to the name. The civilian perspective has extended to a constitutionalist justice with a strong bias of fundamental rights, within a vision of the dignity of the human person and effective protection, either in a direct or indirect way of said right, opening up new arguments so that fact this occurs.

Keywords: Right to Name; Dignity of human person; Constitutional right; Fundamental Rights, Human Rights.

\section{INTRODUÇÃO}

Tradicionalmente visto como Direito da Personalidade, expressão do Direito Civil para identificar o sujeito das relações jurídicas e também indicar um "status" civil, o direito ao nome se apresenta hoje com novos ares.

A ideia deste estudo é demonstrar que a tutela do direito ao nome se deslocou de uma tutela meramente civilista para uma tutela jusconstitucional, a partir do princípio da dignidade da pessoa humana e da necessidade de sua preservação. Os casos concretos apresentados à julgamento em Cortes Internacionais apontaram o direito ao nome como direito à identidade pessoal, como direito à própria origem familiar, como identificador cultural e geoespacial, como direito à intimidade e como expressão do exercício da livre circulação dos povos.

A vertente de pesquisa utilizada foi a jurídico-dogmática, sendo que os tipos de pesquisas desenvolvidas foram os tipos jurídico-descritivo e jurídico-comparativo, usando

\footnotetext{
${ }^{1}$ Graduada em Direito pela Pontifícia Universidade Católica de Minas Gerais; especialista Direito Processual Civil, Universidade Gama Filho, e em Direito Civil, Universidade Cândido Mendes; mestre em Direito Privado, Pontifícia Universidade Católica de Minas Gerais; doutoranda em Direito Publico \& PhD- Estado Social, Constituição e Pobreza, Universidade de Coimbra, Portugal e registradora e tabeliã do Tabelionato de Protesto e Oficio de Títulos e Documentos e Civil de Pessoas Jurídicas de Monte Belo/MG. Email: janiceborges@hotmail.com.
} 
como base sobretudo as decisões da Corte de Estrasburgo e da Corte de Luxemburgo e o direito comparado.

\section{AS NOVAS PERSPECTIVAS DO DIREITO AO NOME}

Após a $2^{\mathrm{a}}$ Guerra Mundial, observou-se nos países ocidentais uma tendência de trazer em suas Constituições conteúdos sociais e de elevar a dignidade da pessoa humana ao plano constitucional como princípio jurídico. O desenvolvimento do modelo social-intervencionista de Estado, contudo, não se mostrou suficiente para superar os problemas econômicos advindos do liberalismo. A situação de um assistencialismo exacerbado levou o Estado a um 'inchaço' de funções e atividades impossíveis de serem mantidas, isto é, a previsão de direito fundamental e sua concretização não foram acompanhadas de dotação orçamentária suficiente para que de fato fosse realizado tal direito.

Visando superar essa perspectiva e dar mais eficiência e melhores resultados à atuação do Estados, os textos constitucionais passaram a possibilitar participações democráticas mais amplas e, a doutrina e jurisprudência, meios mais eficazes de realização efetiva de direito. Para tanto, estudiosos iniciaram trabalhos para indicarem quais fatores poderiam intervir nas citadas situações.

Antes de se adentrar em complexos sistemas de atuação do Estado, com a análise de direitos e deveres sociais a serem observados, diante da latente falta de recursos financeiros e da precisão de um planejamento de atuação setorial por parte da Administração Pública, com verificação de carga tributária e orçamentária, restou-se essencial retornar às bases fornecedoras e mantenedoras de dados que alimentam a ação pública, dentre elas, as que são objeto do presente estudo: a taxa de natalidade e a mobilidade humana.

A taxa de natalidade consiste em um indicador elementar e essencial à organização estatal. Referida taxa reúne informações que permitem estabelecer a quantidade de nascimentos que foram registrados durante certo tempo dentro de uma porcentagem populacional.

A formação dos Estado Nacionais, a separação do Estado e da Igreja e a construção de um estado laico, contudo, exigiram que os nascimentos e as designações nominativas, até então registrados apenas nas paróquias, passassem a ter um caráter burocrático. A partir disso, foram criadas repartições públicas responsáveis pelo registro civil de nascimento, conforme um regime jurídico de nome das pessoas trazido pelos Códigos Civis e por legislações registrais nacionais. Cada Estado Soberano, conforme suas tradições, cultura e costumes, em sua maioria positivados em textos legislativos, traz um regramento próprio, que deve ser observado para que aquele nome escolhido seja reconhecido perante o aparato estatal.

Nesse ponto, deve-se ponderar que as normas positivadas são o reflexo do pressuposto de que as "comunidades pré-constitucionais tem uma identidade própria, expressa em língua, dialecto, práticas sociais, religião, [...], que o Estado Constitucional deve garantir” (TAVARES DA SILVA, 2014).

Partindo dessa ponderação, o reconhecimento estatal do nascimento de uma pessoa passou a ser verificado a partir da realização do registro civil e, a atribuição ao nome, passou a ser uma garantia concedida ao neonato (e em algumas legislações como a brasileira, ao natimorto).

O registro civil faz com que aquela pessoa passe a ter existência nos cadastros e estatísticas governamentais, mas, em que pese a sua importância, não é condição para que seja atribuído um nome à uma pessoa. Na verdade, o registro civil é reconhecimento legal da existência de uma criança, apresentado-se como fundamental para assegurar que ela seja 
contada e tenha acesso a serviços básicos como saúde, segurança social e educação (prestações sociais positivas).

A Convenção da ONU de 1989 , em seu artigo $7^{\circ}$, declara que a criança deve "ser registada imediatamente após o nascimento e tem desde o nascimento o direito a um nome, o direito a adquirir uma nacionalidade e, sempre que possível, o direito de conhecer os seus pais e de ser educada por eles”. Mas, segundo dados da UNICEF, cerca de 230 milhões de crianças menores de cinco anos em todo o mundo nunca foram registrados oficialmente, sendo que no continente asiático se concentra metade dessa parcela.

Essa situação acaba por ocasionar uma “desorientação” na programação de políticas públicas e sociais dos Estados. O mapeamento de nascidos pelo Estado direciona a sua atuação com maior atenção à uma área em detrimento de outra, pois há um planejamento específico orçamentário de prestação de serviços e atividades para atender às regiões com maior taxa de natalidade.

A ausência do registro civil, contudo, macula a existência de pessoas que não possuem sua existência nos cadastros oficiais, mas que, como ser humano que são, merecem igual atendimento em suas necessidades básicas por parte do Estado. Com isso, o Estado não consegue se programar de forma eficaz para direcionar seus recursos (que já são por natureza escassos) no atendimento das demandas urgentes, ao final, a falta de registro de nascimento acaba sendo um dos fatores que dificultam o Estado a se programar e a agir nas prestações sociais. Na verdade, o registro civil oficializa burocraticamente o Direito Fundamental ao nome, inato a todo ser humano. ${ }^{2}$

Além disso, com o passar dos anos, houve uma flexibilização das fronteiras nacionais, em especial, devido ao fluxo migratório e à necessidade de emparelhamento de políticas econômicas para facilitar as transações comerciais. Essa situação acabou por fazer com que os Estados observassem não apenas a taxa de natalidade, mas também a distribuição da população por situação de domicílio, considerando a nacionalidade (ou a binacionalidade) de cada um, para evitar que houvesse grupos excluídos das demandas sociais e uma desarmonia nas legislações nos casos em que mais de um Estado Nacional estivesse envolvido.

Os tratados, acordos e convenções internacionais celebrados visaram confluir as normas de Direitos Humanos, em especial, no que tange ao Direito ao Nome e ao atendimento de direitos sociais, em um único sentido. Mas, se, por um lado, a migração de pessoas e o comércio ampliam as fronteiras, por outro, mostram a necessidade de proteger a cultura, a individualidade e a identidade de cada um, dentro e fora de seu Estado natal.

Nesse ponto, deve-se ressaltar que é na escolha dos sobrenomes, sobretudo dos binacionais, para a formação do nome completo que se encontra a mais complexa e mais diversa questão conflitante em termos legislativos, pois a legislação interna é o resultado da positivação da cultura de um estado nacional que, também, deve ser tutelada.

Na Alemanha, a título de exemplo, o Código Civil, determina a adoção apenas de um sobrenome e, em regra, da linhagem paterna (RODRIGUES JUNIOR, 2013). Em Portugal, a seu turno, admite-se que sobrenomes do pai ou da mãe, ou ainda de ambos, sejam adotados, podendo ainda ser utilizados sobrenomes de antepassados dos pais, ainda que o referido sobrenome não faça parte do nome destes.

\footnotetext{
2 Preocupada com os custo da previdência social a longo prazo, a China emitiu novas diretrizes no final do ano 2015 autorizando casais a gerarem mais de um filho. A política de filho único foi adotada durante anos em território chinês, com a finalidade de conter o crescimento populacional e propiciar o acesso da população aos direitos sociais prestados pelo Estado. Com o extremismo da referida política, muitos casais que tiveram mais de um filho não-registraram os demais para evitar represálias do governo. Com a revisão do posicionamento governamental, ocorreu um aumento da taxa da natalidade, mas alguns defendem que isso, na verdade, é um dado ilusório, pois estaria contabilizando pessoas nascidas há muitos anos e que somente agora foram registradas e contabilizadas oficialmente.
} 
Além do mais, questões ligadas ao nome de casada, divorciada e viúva, nesse último caso a depender da legislação, e os transsexuais, são questões ainda sem solução definitiva e formalizadas em muitas legislações, havendo apenas casos concretos pontuais julgados pelos Tribunais Nacionais e Internacionais, o que faz do tema objeto de estudo eminente e necessário.

Partindo dessas proposições, o direito à receber um nome ${ }^{3}$, em si, assim, consiste em um direito fundamental, inato à condição humana ${ }^{4}$. Ele faz parte do conteúdo do princípio da dignidade da pessoa humana e, partindo dessa noção, consagra-se a ideia de que "em virtude tão somente da condição humana e independentemente de qualquer outra circunstância" (STARLET, 2002) o ser humano é titular de direitos que devem ser reconhecidos e respeitados por seus semelhantes e pelo Estado.

A dignidade da pessoa humana, enquanto princípio jurídico, faz parte do rol dos Direitos Fundamentais que, por sua vez, são interesses reconhecidos pelas normas constitucionais enquanto bens jurídicos pessoais, ainda que os valores que originaram esses interesses possam ser simultaneamente valores comunitários (VIEIRA DE ANDRADE, 2016). Na verdade, a dignidade da pessoa humana representa um dos sustentáculos do constitucionalismo moderno e é base para qualquer legislação nacional ou supranacional referente aos direitos do homem.

Conforme ensina Vieira de Andrade (2016), o princípio da dignidade humana ${ }^{5}$ :

\footnotetext{
${ }^{3}$ O Pacto Internacional sobre os Direitos Civis e Políticos foi firmado em 1966 pela Assembleia-Geral das Nações Unidas com o objetivo de dar maior efetividade à proteção dos direitos decorrentes da dignidade da pessoa humana. Seu artigo 24 é categórico ao afirmar que qualquer criança, sem nenhuma discriminação de raça, cor, sexo, língua, religião, origem nacional ou social, propriedade ou nascimento, tem direito, da parte da sua família, da sociedade e do Estado, às medidas de proteção que exija a sua condição de menor, devendo ser registada imediatamente após o seu nascimento e ter um nome.

${ }^{4}$ Nesse contexto, importante ressaltar que a pessoa humana consiste em uma realidade que "preexiste ao Direito, de modo que o Direito está subordinado a ela. A pessoa define-se e impõe-se por si, não é a lei quem a cria”, mas isso não impede que o Direito desempenhe a função de dar condições de praticabilidade à realidade, atribuindo meios para operacionalizar a vida e dignificar enquanto ser (ASCENSÃO, 2006).

${ }^{5}$ Pertinente observar o pensamento de WEINRIB (2016) sobre dignidade humana: "The animating idea of this theory is human dignity, conceived of in terms of the right of each person to equal free- dom. By systematically unpacking the normative, institutional, and doctrinal ramifications of this simple idea for the public law relationship between rulers and ruled, a theory illuminating modern constitutional practice materializes. By modern constitutional practice, I refer to the sum of conditions that legal systems in the postwar era have introduced to make the exercise of public authority accountable to the human dignity of all who are subject to it. These conditions include a constitution that establishes the terms for the lawful exercise of all public authority; a set of constitutional rights that bind all branches of government; an accessible judicial body authorized and obligated to respond to constitutional complaints by reviewing the conformity of government conduct to constitutional norms; substantive constraints on the amending power that preserve the essentials of the constitutional order; and doctrines that determine both the protections that constitutional rights afford and the limits to which rights are subject in reference to the overarching idea of human dignity. Together these conditions create, sustain, and refine a legal order in which the human dignity of each person forms a justiciable constraint on the exercise of all public authority. HABERMAS (2004), por sua vez, defende que a dignidade humana não é uma propriedade que se pode 'possuir' por natureza. Ela marca a 'intangibilidade' da vida humana, a qual só pode ter significado nas relações interpessoais de reconhecimento recíproco e no relacionamento igualitário entre as pessoas. Nesse contexto, importante salientar que Habermas diferencia a dignidade da vida humana e a dignidade da pessoa humana. A dignidade da vida humana consiste no respeito que todos devem ter diante da vida humana. A dignidade da pessoa humana, a seu turno, refere-se à construção individual da história de vida de uma pessoa, por meio da socialização, isto é, no contexto público de integração de um mundo da vida partilhado intersubjetivamente. Todavia, o conceito de dignidade humana sempre foi permeado de divergências, no presente estudo, assim como fez VIEIRA DE ANDRADE (2016), delimita-se a afirmar que o que importa é "apenas a afirmação da ideia de uma dignidadevalor, reconhecida pelo Direito a cada indivíduo pelo faeto de ele ser pessoa, independentemente de saber se isso constitui uma enteléquia (uma essência em si), uma representação ou o nome para o conjunto de necessidade características do homem como ser espiritual indeterminado e inespecífico (mesmo que seja visto como um 'animal de espírito adoecido’”.
} 
está na base do estatuto jurídico dos indivíduos e confere unidade de sentido ao conjunto de preceitos relativos aos direitos fundamentais. Esses preceitos não se justificam isoladamente pela proteção de bens jurídicos avulsos, só ganham sentido enquanto ordem que manifesta o respeito pela unidade existencial de sentido que cada homem é para além dos seus atos e atributos.

A dignidade humana, em que pese ser passível de uma leitura estreita com o contexto histórico-político e sociocultural, possui, como denominador comum, uma amplitude que engloba o direito à vida, à identidade e à integridade pessoal, à liberdade física e de consciência, como manifestações explícitas diretas e concretas à respeito da condição humana. Acrescentase que em circunstâncias particulares, situações sociais, econômicas, políticas e ideológicas também podem envolver o princípio normativo em questão, para dar proteção integral da espécie e do ser humano.

Outro ponto que se deve atentar é que a invocação do princípio da dignidade deve ser respaldada em cautela, pois o princípio:

não pode servir para toda e qualquer hipótese de tutela à pessoa; não pode substituir o direito de personalidade; não pode atuar sempre como prima ratio na argumentação judicial, para o efeito de afastar outros princípios e regras; não pode, enfim, ter a sua especificidade, sob pena de transforma-se, rapidamente, em flatus vocis” (RIO GRANDE DO SUL. Tribunal de Justiça. Apelação civil n. 70002511806. Rel. Des. Mara Larsen Chechi apud MARTINS-COSTA, 2006).

Isso porque a invocação desmedida ao princípio da dignidade ocasiona a perda de centralidade de seu "ethos" e, por via de consequência, provoca sua mobilização para fundamentar decisões em casos que estão bastante distantes dos problemas que, de fato, deveriam ter a sua presença requisitada (TAVARES DA SILVA, 2014). Se se usa o princípio da dignidade da pessoa para tudo, o esvazia em termos de conteúdo normativo e valorativo.

No presente estudo, o sentido dado ao princípio da dignidade da pessoa humana é o direito subjetivo que permite reivindicar prestações positivas no contexto à garantia de um mínimo de recursos para uma existência condigna, sendo a sua análise condicionada à preexistência ou não, no ordenamento jurídico, de outros princípios que possam ser mais bem aplicados ao caso concreto, à presença de regras ou postulados que melhor direcionam e fundamentam a resposta adequada ao caso real, e, por fim, se realmente o caso é de agressão à vida humana digna.

Com relação especificamente ao direito ao nome, dentre os diplomas editados pela Comissão Internacional do Estado Civil, criada em 1948, tem-se a Convenção relativa à alteração de nomes próprios e sobrenomes de 4 de setembro de 1959 e Convenção de 05 de setembro de 1980, sobre a lei aplicável aos nomes próprios e sobrenomes, sendo esta última com a finalidade de promover a unificação do direito relativo ao nome próprio e sobrenomes, por meio da adoção de regras comuns de direito internacional privado. A segunda convenção foi mais específica que a anterior, tratando a matéria de forma mais pontual. De acordo com seu art. $1^{\circ}$, o nome próprio e o sobrenome de cada pessoa são determinados pela lei do seu Estado de origem e em caso de mudança de nacionalidade, aplicar-se-á a lei do Estado da nova nacionalidade.

Reconhecido o direito ao nome como direito fundamental pertencente à gama de direitos derivados do princípio da dignidade da pessoa humana presente nos textos constitucionais, a questão reflete nos Direitos da Personalidade, de modo a considerar o direito ao nome como um dos atributos da personalidade e, por fim, a matéria é exaustivamente tratada pelo Direito Registral, que traça linhas limitantes ao exercício desse direito, como por exemplo, a forma de grafia de nomes estrangeiros e normas sobre a adoção de sobrenomes. 
Com efeito, o reconhecimento do direito ao nome apresenta-se como uma realidade no ordenamento jurídico. Mas, a forma com que a proteção ao direito ao nome é conferida é distinta. O nome pode ser tutelado sob as bases do direito a conhecer a própria origem, sob o direito de pertencer a uma certa cultura dentro de uma dimensão geoespacial, como identificador familiar e pessoal, como integrante do direito à intimidade e como uma das formas de manifestação da liberdade de circulação territorial.

O direito ao conhecimento da própria origem ganhou relevância nos contornos atuais em razão dos avanços da Bioética, com a possibilidade dos exames de DNA para atribuição de paternidade e com a hipóteses que possibilitam de quebra no sigilo das adoções para conhecimento da identidade genética. O direito à origem perpassa o caráter biológico, fisionômico, mas a eles não se restringe. $\mathrm{O}$ direito à origem ${ }^{6}$ é atribuído a cada um, com a finalidade de conhecer seus antepassados, o local onde ocorreu o nascimento, o local onde a família estabeleceu moradia, as manifestações culturais daquele clã familiar e tudo que, de alguma forma, possa individualizar o ser humano, conectando-o ao seu passado, ao pertencimento a um determinado grupo e a uma região geoespacial.

O direito à cultura não se resume ao direito a receber e ter sua cultura local preservada pelos órgãos estatais e demais sociedades e indivíduos. Na verdade, o direito à cultura interage com um direito muito mais amplo que é o de ter uma nacionalidade e de ser reconhecido como cidadão daquele território, merecedor de proteção jurídica em seus costumes e tradições e de participar das decisões políticas locais.

Ao participar da vida política, por meio de seus representantes, ou ainda de qualquer modo que a legislação nacional possibilite, o cidadão faz parte da elaboração das normas que o regulam como membro de uma sociedade, sendo as normas textos que refletem a cultura local, que deve ser preservada. A Corte de Estrasburgo chegou a reconhecer o direito ao nome como direito fundamental, mas demonstrou uma tendência a considerar as normas estatais internas, mesmo em casos em que aplicação da legislação local implique em uma alteração na grafia do nome, como foi o caso Mentzen/Mencena. Privilegiou-se a legislação interna, preservando a cultura nacional, e afastou-se o direito à identidade, não considerando os inconvenientes ocasionados por essa medida na vida prática das pessoas envolvidas. A Corte optou pela preservação da cultura dos povos mesmo em países que possuem uma legislação que vai na contramão da atualidade ou da maioria dos países, como é o caso da Letônia.

O direito à identidade, a seu turno, nos dizeres de Adriano de Cupis (2004), se justifica pelo fato de que o indivíduo, como unidade da vida social e jurídica, necessita de afirmar a própria individualidade, de modo a se distinguir dos demais indivíduos e, por consequência, ser conhecido por quem é na realidade. Aduz que "o bem que satisfaz esta necessidade é o da identidade, o qual consiste, precisamente, no distinguir-se das outras pessoas nas relações sociais", assim, o homem não se firma como pessoa, mas sim como certa pessoa. O direito ao nome é um direito de identificação pessoal, é um "meio de realização do bem da identidade" (PINTO, 2003).

Os estudos sobre o direito à identidade pessoal remontam ao direito italiano (diritto su se stesso) (RESCIGNO, 1981), em especial à decisão da Corte Italiana (1985) ${ }^{7}$, que assinalou

\footnotetext{
${ }^{6}$ No Brasil, "o direito à busca da ancestralidade é personalíssimo e, dessa forma, possui tutela jurídica integral e especial, nos moldes dos arts. $5^{\circ}$ e 226, da Constituição da República de 1988. O art. 1.591 do Código Civil de 2002, ao regular as relações de parentesco em linha reta, não estipula limitação, dada a sua infinitude, de modo que todas as pessoas oriundas de um tronco ancestral comum, sempre serão consideradas parentes entre si, por mais afastadas que estejam as gerações; dessa forma, uma vez declarada a existência de relação de parentesco na linha reta a partir do segundo grau, esta gerará todos os efeitos que o parentesco em primeiro grau (filiação) faria nascer”, conforme decisão do Superior Tribunal de Justiça (BRASIL, 2010).

${ }^{7}$ Prosser e Keeton (1984) ressaltam que antes da mencionada decisão italiana, no direito anglo-saxônico enfocouse o tema, contudo dentro do direito à intimidade.
} 
que cada sujeito tem interesse de ser apresentado na sua vida social com sua verdadeira identidade, tal como esta é conhecida ou poderia ser conhecida. Isso faz com que a identidade pessoal consista em um bem em si mesmo, independente da condição pessoal e social, das virtudes e dos defeitos do sujeito, de modo que, a cada um é reconhecido o direito a que sua individualização seja devidamente preservada e tutelada.

Os primeiros debates sobre a defesa do nome como identidade pessoal estão relacionados ao nome de casada da mulher que acresceu o sobrenome do marido ao seu (ROSSOLILLO). A situação ganhou relevância após a propagação, em diversos ordenamentos, das legislações sobre o divórcio e a possibilidade (ou não) de voltar a mulher a assinar o nome de solteira. Com a evolução da doutrina e da jurisprudência, o nome de casada saiu do status "família” para o "identidade pessoal”, e a mulher passou a ter a opção de aderir ou não a adoção do nome de família do marido e a permanecer ou não com o sobrenome em caso de eventual divórcio, em países como o Brasil.

Outro ponto a ser ressaltado dentro do direito à intimidade é que as condições pessoais abrangidas pelo direito à identidade abarca o ser humano em sua inteireza, inclusive a identidade de gênero da pessoa. Nesse sentido, o Superior Tribunal de Justiça estendeu o direito à mudança do prenome, ensejador de situação vexatória ou degradação social, aos transexuais não operados ${ }^{8}$ (ou ainda não operados), "conferindo-se, assim, a máxima efetividade ao princípio constitucional da promoção da dignidade da pessoa humana, cláusula geral de tutela dos direitos existenciais inerentes à personalidade, a qual, hodiernamente, é concebida como valor fundamental do ordenamento jurídico, o que implica o dever inarredável de respeito às diferenças” (BRASIL, 2017).

Ainda segundo a decisão, "sob essa ótica, devem ser resguardados os direitos fundamentais das pessoas transexuais não operadas à identidade (tratamento social de acordo com sua identidade de gênero), à liberdade de desenvolvimento e de expressão da personalidade humana (sem indevida intromissão estatal), ao reconhecimento perante a lei (independentemente da realização de procedimentos médicos), à intimidade e à privacidade (proteção das escolhas de vida), à igualdade e a não discriminação (eliminação de desigualdades fáticas que venham a colocá-los em situação de inferioridade), à saúde (garantia do bem estar biopsicofísico) e à felicidade (bem-estar geral)” (BRASIL, 2017).

Entrelaçado com o direito à identidade, mas sem com ele se confundir, tem-se o direito à intimidade. A tutela da intimidade da vida privada e familiar, especialmente do núcleo convivente, ganhou relevância à medida que se passou a entender que o ser humano faz parte de uma família é detentor de um status familiare. "A situação do indivíduo é complexa, comporta tanto direitos como deveres em relação aos componentes do núcleo familiar, uns e outros fundados na unidade e na solidariedade familiar e nas obrigações juridicamente relevantes nas especiais relações (de cônjuge, de filiação) reforçadas pela convivência" (PERLINGIERI, 2008). Nesse diapasão, a tutela da intimidade relaciona-se à pessoa como integrante de um núcleo familiar.

Em sede jurisprudencial, a Corte de Estrasburgo ${ }^{9}$ talvez seja o Tribunal que mais visualizou a defesa do nome por meio do direito à intimidade. Em várias situações, afirmou o

\footnotetext{
${ }^{8}$ Os Tribunais brasileiros ja vinham concedendo a alteração de prenome aos transsexuais que se submeteram à cirurgia de mudança de sexo, por entenderem que "A afirmação da identidade sexual, compreendida pela identidade humana, encerra a realização da dignidade, no que tange à possibilidade de expressar todos os atributos e características do gênero imanente a cada pessoa. Para o transexual, ter uma vida digna importa em ver reconhecida a sua identidade sexual, sob a ótica psicossocial, a refletir a verdade real por ele vivenciada e que se reflete na sociedade" (BRASIL. 2009).

${ }^{9}$ Dentre os casos julgados por essa Corte, destaca-se: Caso Guillot c. França (Pedido n. 22500/93), Caso Burghartz c. Suíça, (Pedido n. 16213/90), Caso Stjerna c. Finlândia (Pedido n. 18131/91), Caso Gianettoni e Fornaciarini c. Suíça (Pedido n. 22940/93), Caso Salonen c. Finlândia (Requerimento n. 27868/95), Caso Sijka c. Polonia (Pedido
} 
direito ao nome como um dos elementos de identificação pessoal e como elo com a família e com a vida privada, conferindo proteção a esse direito nos termos do artigo $8^{\circ}$ da CEDU, comando normativo protetor do direito à intimidade. O Tribunal também utilizou o artigo $14^{\circ}$ da Convenção como meio de proteção a esse direito, quando a questão envolvesse discriminação em razão do sexo na relação familiar, e neste ponto, o direito ao nome ganhou status significante dentro da abordagem do direito à igualdade e a não discriminação.

O fluxo comercial e imigratório de pessoas ampliaram fronteiras e a formação de blocos ou comunidade econômicas exigiram uma maior interação entre os países para proteger não apenas os interesses econômicos-comerciais, mas também os próprios direitos do homem.

No caso europeu, o direito comunitário apresenta-se como uma realidade e as regras que regem o sobrenome de uma pessoa são da competência dos Estados-Membros, cabendo a eles, a princípio, regular a matéria. No entanto, as normas materiais nacionais devem ser lidas e interpretadas em consonância com o regulamento comunitário. Em casos de binacionais ${ }^{10}$, originários de países membros da União Europeia, cada um dos Estados Nacionais membros devem observância prioritária ao ordenamento jurídico comunitário e depois ao ordenamento jurídico nacional, sob pena de subversão às normas de direitos fundamentais assegurados no pacto comunitário e à manutenção do próprio sistema.

O contexto atual, marcado sobremaneira pela ideia de cooperação entre os países e o aumento da complexidade das relações sociais, ocasionaram situações em que não se limitavam ao direito interno ou, ainda, em que o direito interno poderia ir contra as normas comunitárias. Nesse diapasão, a proteção ao direito ao nome passa a ter um novo parâmetro, decorrente de uma noção muito mais ampla, que é a condição de cidadão europeu, condição essa que corresponde à obrigatoriedade do recíproco reconhecimento do status pessoal e familiar das pessoas dentro da União Europeia e sua liberdade de circulação nos territórios dos Estados Membros e a não discriminação em razão da origem

Em três oportunidades (Caso Konstantinidis, Garcia Avello e Niebull, Grunkin e Paul), a Corte de Luxemburgo optou por uma proteção ao direito ao nome de forma indireta, isto é, assegurou o direito ao nome como requerido, utilizando como arcabouço jurídico não o direito fundamental à identidade (ou ainda o direito à intimidade, como o TEDH), mas à livre circulação de pessoas, aos direitos dos associados e à não discriminação em razão da nacionalidade como projeções sobre o direito ao nome.

Moura Ramos (2013) destaca o trabalho do Tribunal de Justiça, que não se restringiu à ideia de liberdade de circulação a pontos econômicos, mas alargou seu âmbito de aplicação à situações pessoais de um conjunto de regimes nacionais a titulares para os quais não tinham sido inicialmente pensados, abrindo aos nacionais dos demais Estados Membros da União Europeia direitos antes reservados apenas aos nacionais dos seus Estados Membros, em nome da liberdade de circulação.

Tratando-se especificamente do direito ao nome, ao adotar esse posicionamento, a Corte, ao mesmo tempo, ampliou, como já havia feito em outras situações, a dimensão dada ao

n. 26272/95), Caso Szokoloczy-Syllaba c. Suíça (Pedido n. 41843/98), Caso Bijleveld c. Países Baixos (Pedido n. 42973/98), Caso G.M.B. e K. M. c. Suíça. (Pedido n. 36797/97), Caso Üna Tekeli c. Turquia (Requerimento n. 29865/96), Caso Johansson c. Finlândia (Pedido n.10163/02), Caso Daróczy c. Hungria (Pedido n. 44378/05), Caso Gözel Erdogoz c. Turquia (Pedido n. 37483/02) e Caso Kismoun c. França (Pedido n. 32265/10).

${ }^{10}$ A questão dos binacionais traz a necessidade de harmonização entre os ordenamentos jurídicos nacionais envolvidos e a existência (ou não) de algum Tratado, Acordo ou Convenção internacional a ser observada. Países como Portugal e Brasil admitem a adoção do sobrenome materno e paterno, em conjunto. Outros países, como a Itália, aderem a regra a atribuição do sobrenome paterno. E, ainda tem países como a Suíça que adotam a escolha do sobrenome de família (podendo ser ou o materno ou o paterno, desde que seja apenas um o escolhido). Aos detentores de dupla nacionalidade abrem-se as possibilidades de escolher qual legislação deve ser aplicada: a do local do nascimento do sujeito ou de seus pais, ou a do local de domicílio ou residência do sujeito ou dos seus pais. 
direito ao nome e instituiu novas perspectivas aos princípios da livre circulação de pessoas e aos demais princípios citados, na medida em que esses não mais se restrigem ao direito de ir e vir em um sentido estrito de liberdade de locomoção ou a meras questões comerciais, mas envolve também situações ligadas à direitos existênciais (entendendo este como um direito não patrimonial).

Essas decisões obrigaram uma nova interpretação na legislação interna ${ }^{11}$. Na ocasião dos referidos julgados, o direito ao nome, na União Europeia, passou a ter dois significados (TOMASI): o direito à escolha do sobrenome adotado, bem como a continuidade de sobrenome para além das fronteiras nacionais dos países membros e também a escolha de qual será a legislação nacional a regular o direito à escolha do nome. Isso, quando o caso envolver dois ou mais ordenamentos nacionais, dentro do princípio da unidade de status, com base na não discriminação e na liberdade de circulação (como nos casos Konstantinidis e Garcia Avello) e na conservação transnacional do nome, visto pela perspectiva da liberdade de circulação (como apresentado em Grunkin e Paul).

Desta forma, pode-se observar que em que pese o princípio da dignidade da pessoa humana ter sido o fundamento matricial de uma proteção constitucional do direito ao nome, tanto no âmbito interno quanto internacional, os tribunais conferiram proteção ao direito ao nome, de forma direta ou indireta, por meio de princípios próprios e específicos como o direito à identidade constitucional e à intimidade; e ainda, estenderam conceitos como nos casos do direito à própria origem, direito à preservação da cultura e do exercício das liberdades fundamentais nos termos da livre circulação dos povos.

\section{CONSIDERAÇÕES}

A proteção ao nome, independente do contorno adotado, deve ter em vista a efetiva proteção dos direitos humanos, em seu maior grau de extensão. O importante é que a tutela dos direitos fundamentais ganha, cada dia mais, mecanismos para que a vasta gama desses direitos seja efetivada, pois para a Ciência do Direito, a proteção da pessoa humana e todos os aspectos a ela correlacionados é questão primordial que insurge em todos os ordenamentos jurídicos vigentes de todos os países.

Os casos concretos existem e são postos frente ao Poder Jurisdicional, situação que faz com que os estudiosos do Direito busquem, em trabalhos hermenêuticos correlacionados aos Direitos Fundamentais, ao Direito Internacional, aos princípios constitucionais e aos princípios do direito privado e do direito registral, uma possível resposta a ser dada e justifica a produção da pesquisa acadêmica ora proposta.

\section{REFERÊNCIAS}

ASCENSÃO, José de Oliveira. A pessoa: entre o formalismo e a realidade ética. Revista EMERJ. v. 9, n. 33, 2006, pp. 93-116.

\footnotetext{
${ }^{11}$ No caso italiano, a tradição que afirmava que ao nascer a criança recebia automaticamente um único sobrenome, o paterno, foi considerada, em 2014, pela Corte Europeia de Direitos Humanos "patriarcal e discriminatória" (ITALIA, 2016). A rigidez da aplicação da norma italiana era tamanha que países como o Brasil, flexibilizaram suas normas internas, para atender os casos dos binacionais ítalo-brasileiros, como no caso decidido pelo Superior Tribunal de Justiça, em que restou admitido a modificação do nome civil quando, em virtude da dupla cidadania, houver diferença entre os nomes registrados nos documentos brasileiros e italianos. "Isso porque há justo motivo para a uniformização dos registros, à luz dos princípios da verdade real e da simetria. Além disso, a medida evita transtornos nos atos da vida civil e preserva terceiros quanto à eventuais prejuízos (BRASIL, 2017).
} 
BRASIL: Superior Tribunal de Justiça. REsp 1008398/SP. Relatora Min. NANCY ANDRIGHI. $3^{\text {a }}$ Turma. Publicado em: 18 de novembro de 2009.

BRASIL: Superior Tribunal de Justiça. REsp 807849/RJ. Relatora Min. NANCY ANDRIGHI. $2^{\circ}$ Seção. Publicado em: 06 de agosto de 2010.

BRASIL: Superior Tribunal de Justiça. REsp 1310088/MG, 2017.

BRASIL: Superior Tribunal de Justiça. REsp 1626739/RS. Relator Min. LUIS FELIPE SALOMÃO. $4^{\mathrm{a}}$ Turma. Publicado em: 01 de agosto de 2017.

DE CUPIS, Adriano. Os direitos da personalidade. $1^{\circ}$ ed. Trad. Afonso Celso Furtado Rezende. Campinas: Romana, 2004.

HABERMAS, Jurgen. O futuro da natureza humana. Trad. Karina Jannini, Martins Fontes, São Paulo, 2004.

ITALIA: Corte Costituzionale - Senteza n. 13/94 e Acordão de 22 de junho de 1985.

ITALIA: Corte Costituzionale- Sentenza n. 286, 8 novembre - 21 dicembre 2016.

LORENZETTI, Ricardo Luis. Fundamentos do Direito Privado. Trad. Vera Maria Jacob de Fradera. São Paulo: RT, 1998.

MARTINS-COSTA, Judith. Pessoa, Personalidade, Dignidade: ensaio de uma qualificação, tese de livre-docência em Direito Civil apresentada à Congregação da Faculdade de Direito da Universidade de São Paulo, maio, 2003.

MOURA RAMOS, Rui Manuel Gens de. Da Livre circulação de pessoas à cidadania europeia. In MOURA RAMOS, Rui Manuel Gens de. Estudos de Direito da União Europeia, Coimbra Editora. Coimbra: 2013.

ONU. Convenção Internacional sobre os direitos das crianças. Disponível em: https://www.unicef.pt/docs/pdf_publicacoes/convencao_direitos_crianca2004.pdf, acesso em 05 de janeiro de 2017.

PERLINGIERI, Pietro. O direito civil na legalidade constitucional. Rio de Janeiro: Renovar, 2008.

PINTO, Paulo Mota. Direitos de personalidade no Código Civil Português e Brasileiro. Revista Jurídica 314, dez, 2003, p. 7- 34.

PORTUGAL. Código do Registro Civil. Decreto Lei n. 131/95. Artigos 103 e 104.

PROSSER e KEETON, On torts. West Publishing Co., St Minnesota, 1984.

RESCIGNO, Pietro. Tratado do Diritto Privato. Utetm, Torino, 1982; Il diritto alla identità personale, Cedam, Padova, 1981. 
RODRIGUES JUNIOR, Otavio Luiz. A influência do BGB e da doutrina alemã no Direito Civil brasileiro do século XX. Revista dos Tribunais. São Paulo, V. 102, n. 938, pp. 79-155, dez. 2013.

ROSSOLILLO, Giulia. Identità personale e diritto internazionale privato. Pubblicazioni della Università di Pavia - studi nelle scienze giuriche e sociali, v. 135, Pavia, pp. 9.

STARLET, Inglo Wolfgang. Dignidade da Pessoa Humana e Direitos Fundamentais na Constituição Federal de 1988. Porto Alegre: Livraria do Advogado, 2002.

TAVARES DA SILVA, Suzana. Direitos Fundamentais na arena global. $2^{\circ}$ ed. Coimbra: Imprensa da Universidade de Coimbra, 2014.

TOMASI, Laura. Il Diritto al nome tra libertà di circolazione e Diritti Fondamentali In HONORATI Costanza (org.). Diritto al nome e all identità personale. Collana diretta da Fausto Pocar, L’Italia e la vita giuridica internazionale n. 29, Giuffrè Editore.

UNIAO EUROPEIA: Tribunal Europeu de Direitos Humanos. Pedido n. 71074/01. Caso Mentzen/ Mencena c. Letônia.

UNIAO EUROPEIA: Tribunal Europeu de Direitos Humanos. Caso Guillot c. França. Pedido n. 22500/93.

UNIAO EUROPEIA: Tribunal Europeu de Direitos Humanos. Caso Burghartz c. Suíça. Pedido n. 16213/90.

UNIAO EUROPEIA: Tribunal Europeu de Direitos Humanos. Caso Stjerna c. Finlândia. Pedido n. 18131/91.

UNIAO EUROPEIA: Tribunal Europeu de Direitos Humanos. Caso Gianettoni e Fornaciarini c. Suíça. Pedido n. 22940/93.

UNIAO EUROPEIA: Tribunal Europeu de Direitos Humanos. Caso Salonen c. Finlândia. Requerimento n. 27868/95.

UNIAO EUROPEIA: Tribunal Europeu de Direitos Humanos. Caso. Caso Sijka c. Polonia. Pedido n. 26272/95.

UNIAO EUROPEIA: Tribunal Europeu de Direitos Humanos. Caso Szokoloczy-Syllaba c. Suíça. Pedido n. 41843/98.

UNIAO EUROPEIA: Tribunal Europeu de Direitos Humanos. Caso Bijleveld c. Países Baixos. Pedido n. 42973/98.

UNIAO EUROPEIA: Tribunal Europeu de Direitos Humanos. Caso G.M.B. e K. M. c. Suíça. Pedido n. 36797/97.

UNIAO EUROPEIA: Tribunal Europeu de Direitos Humanos. Caso Üna Tekeli c. Turquia. Requerimento n. 29865/96). 
UNIAO EUROPEIA: Tribunal Europeu de Direitos Humanos. Caso Johansson c. Finlândia. Pedido n.10163/02.

UNIAO EUROPEIA: Tribunal Europeu de Direitos Humanos. Caso Daróczy c. Hungria. Pedido n. 44378/05.

UNIAO EUROPEIA: Tribunal Europeu de Direitos Humanos. Caso Gözel Erdogoz c. Turquia. Pedido n. 37483/02).

UNIAO EUROPEIA: Tribunal Europeu de Direitos Humanos. Pedido n. 32265/10. Caso Kismoun c. França.

UNIAO EUROPEIA: Tribunal Europeu dos Direito do Homem. Pedido C-168/91. Caso Konstantinidis.

UNIAO EUROPEIA: Tribunal de Justiça da União Europeia. Pedido C-148/02. Caso Garcia Avello.

UNIAO EUROPEIA: Tribunal de Justiça da União Europeia. Pedido n. C-353/06. Caso Niebull, Grunkin e Paul.

UNICEF. Disponível em https://www.unicef.org/protection/57929_58010.html, acesso em 27 de agosto de 2017.

VIERA DE ANDRADE, José Carlos. Os direitos fundamentais na Constituição Portuguesa de 1976. $5^{\circ}$ ed. Coimbra: Almedina, 2016.

WEINRIB, Jacob. Dimensions of Dignity - the theory and practice of modern constitutional law. Cambridge University Press, Cambridge, 2016. 